\title{
Photobiomodulation Therapy in the Treatment of Oral Mucositis, Dysgeusia and Oral Dryness as Side-Effects of Head and Neck Radiotherapy in a Cancer Patient: A Case Report
}

\author{
Marwan El Mobadder ${ }^{1, *}$, Fadi Farhat ${ }^{2}$, Wassim El Mobadder ${ }^{3}$ and Samir Nammour ${ }^{1}$ \\ 1 Department of Dental Science, Faculty of Medicine, University of Liège, 4000 Liège, Belgium; \\ S.Namour@ulg.ac.be \\ 2 Department of Hematology and Oncology, Hammoud Hospital University Medical Centre, \\ 652 Saida, Lebanon; drfadi.research@gmail.com \\ 3 Department of Endodontics, Faculty of dental medicine, University Saint Joseph, Beirut 1107 2050, Lebanon; \\ drmobader@gmail.com \\ * Correspondence: m.mobadder@student.uliege.be; Tel.: +961-71-343-767
}

Received: 29 September 2018; Accepted: 7 November 2018; Published: 10 November 2018

check for updates

\begin{abstract}
Successful management of oral mucositis, dysgeusia and oral dryness was made with five sessions of photobiomodulation. The severity of oral mucositis was measured according to the World Health Organization scale for the assessment of oral mucositis. Dysgeusia testing was performed according to the International Standards Organization (ISO). For the assessment of oral dryness or hyposalivation, quantity of the total resting and stimulated saliva (Q-sal, $\mathrm{mL} / \mathrm{min}$ ) was measured. Photobiomodulation parameters, applications, and treatment protocol used were suggested by an international multidisciplinary panel of clinicians and researchers with expertise in the area of supportive care in cancer and/or PBM clinical application and dosimetry. This case report confirms the effectiveness of photobiomodulation therapy in the management of oral mucositis, dysgeusia, and oral dryness.
\end{abstract}

Keywords: photobiomodulation; low-level laser therapy; dysgeusia; oral mucositis; oral dryness; hyposalivation; cancer

\section{Introduction}

Photobiomodulation (PBM) therapy is defined as a form of light therapy. Visible, infrared and near infrared light is absorbed by endogenous chromophores, triggering biological reactions that are not thermal or cytotoxic through photochemical or photophysical events, leading to physiological changes. It is now established that radiation at certain wavelengths can modulate living cells and tissues [1]. Photobiomodulation was previously known as low-level laser therapy because the light used is of low intensity compared to other forms of medical laser treatments, which are mainly used for surgery [1]. Recent data suggests that the mechanism of action of PBM is predominantly related to an action on cytochrome c oxidase $(\mathrm{CcO})$ in the mitochondrial respiratory chain by facilitating electron transport $[2,3]$. This, therefore, results in an increased transmembrane proton gradient, which drives adenosine triphosphate (ATP) production, and in an increased bioavailability to power the functions of cellular metabolism [2,3]. PBM enhances wound repair and tissue regeneration by acting on different phases of injury resolution, including inflammation, proliferation, and remodeling phases [4].

Chemotherapy (CT) and/or radiotherapy (RT) are effective treatment modalities for cancer patients. Nevertheless, these treatments are associated with side-effects such as mucositis, dysphagia, 
dysgeusia, radiation dermatitis, xerostomia or hyposalivation, and head and neck lymphedema, among others [5]. In fact, $80 \%$ of patients receiving a high dose of CT prior to hematopoietic stem cell transplantation (HSCT) manifest oral mucositis. Patients receiving conventional CT for solid tumors have a $20-40 \%$ risk of manifesting oral mucositis, whereas patients receiving head and neck RT have an $80 \%$ risk of the same [6]. 63-93\% of patients exhibit xerostomia or hyposalivation when the zone of radiation includes the salivary glands [7]. Dysgeusiais was found in approximately $66.5 \%$ of patients receiving head and neck RT alone and in $76.0 \%$ of patients after they have undertaken head and neck chimioradiotherapy (CRT) [8]. Approximately $15 \%$ of patients continue to experience dysgeusia after treatment [8].

The use of PBM has recently shown significant promise for supportive cancer care measures [9]. In fact, the Multinational Association of Supportive Care in Cancer and the International Society of Oral Oncology recommend the use of photobiomodulation for the prevention of oral mucositis in two cases: for patients having head and neck cancer and for patients before undergoing hematopoietic stem cell transplant $[10,11]$. On the other hand, an international multidisciplinary panel of clinicians and researchers with expertise in the area of supportive care in cancer and/or PBM clinical application and dosimetry have recently suggested treatment protocols in the management of side effects due to radio and/or chemotherapy. Different protocols have been proposed for the prevention and treatment of the following complications: oral mucositis, dysphagia, dysgeusia, hyposalivation or xerostomia, Radiation dermatitis, trismus, osteonecrosis, head and neck lymphedema and voice speech alteration due to local inflammation $[8,9]$.

\section{Case Report}

A 48-year-old male patient diagnosed with adenocarcinoma consistent with salivary duct carcinoma T4a ( $40 \mathrm{~mm}$ ) N2 (multiple focal $1 \mathrm{~cm}$ right submandibular and retrocervical nodes) M0/stage IVA. Surgical excision was not recommended; the patient underwent Intensity-ModulatedRadiation Therapy with a curative aim for 44 days. After radiotherapy, the patient started to complain of pain, dysgeusia, and oral dryness, which persisted with time. Oral mucositis, dysgeusia, and oral dryness were diagnosed based on a meticulous clinical examination. No ethical committee approval was necessary for our research since the protocol used in this case report is well described in the literature. The patient signed a written informed consent before enrolling in the study.

Assessment of oral mucositis

The severity of oral mucositis was measured according to the World Health Organization scale for assessing oral mucositis. The patient presented erythema and ulcers but was able to eat solid foods; therefore, the severity of oral mucositis was Grade 2 (Table 1).

Assessment of dysgeusia

According to the International Standards Organization (ISO), dysgeusia test was used in order to assess the severity of the disorder. Before all taste tests, the patient was asked to stop eating, drinking, smoking or using any oral care products. The patient was also required to drink only water at least one hour prior to testing. Five 2-mm solutions that represent basic taste qualities-sweet, salty, sour, bitter and umami-were tasted in a single 'sip and spit' technique. The solutions and their corresponding concentrations were sucrose $300 \mathrm{mM}, \mathrm{NaCl} 200 \mathrm{mM}$, citric acid $5 \mathrm{mM}$, caffeine $10 \mathrm{mM}$, and MSG $200 \mathrm{mM}$. Perceived taste quality was identified by selecting one of seven choices. Correct responses were sweet for sucrose, salty for $\mathrm{NaCl}$, sour for citric acid, bitter for caffeine, and savory for MSG. Further choices were none or metallic. Taste identification score was assigned as $0-5$ correct choices. The test identification score was 3 out of 5 . The mouth was rinsed with purified water 3 times before and after sampling and expectorating each solution (Table 1).

Assessment of oral dryness

For the assessment of oral dryness or hyposalivation, the quantity of the total resting and stimulated saliva (Q-sal, $\mathrm{mL} / \mathrm{min}$ ) was measured. The patient was asked to expectorate all saliva into a graduated test tube for a 10-min period before the citric acid stimulation and a 5 -min period after the 
stimulation. The amount of saliva before and after stimulation was determined by the scale on the graduated tube. The quantity of saliva was respectively 0.05 and 0.11 for the resting and stimulating saliva [12]. After the assessment of the severity of oral mucositis, dysgeusia, and oral dryness, the treatment of choice was the therapeutic (curative) use of photobiomodulation (low-level laser therapy) for at least 5 times a week until there was an improvement in symptoms. Photobiomodulation dosimetry, applications, and treatment protocol was based on evidence derived from the literature and expert opinion that provided a guideline for the use of photobiomodulation in supportive cancer care for oral mucositis, dysgeusia and oral dryness [9] (Table 1).

i. Treatment of oral mucositis

Intraoral application of diode laser is employed with a wavelength of $980 \mathrm{~nm}$ (FONA Laser Sirona Dental Systems $\mathrm{GmbH}$, Germany) at energy density of $4 \mathrm{~J} /$ point and a time of $12 \mathrm{~s}$ per point in a continuous and contact mode on 4 points on the tongue and 2 on the oropharynx. Extraoral application of diode laser is achieved with a wavelength of $980 \mathrm{~nm}$ (FONA Laser Sirona Dental Systems GmbH, Germany), energy density of $4 \mathrm{~J} /$ point, and a time of $12 \mathrm{~s}$ per point on the following areas: lips, cutaneous surface corresponding to the buccal mucosae, and bilateral cervical lymphaphatic chain [9] (Table 2).

ii. Treatment of dysgeusia

Intraoral application of diode laser is achieved with a wavelength of $980 \mathrm{~nm}$ (FONA Laser Sirona Dental Systems, GmbH, Germany) at 10 points on the dorsal and lateral tongue at an energy density of $3 \mathrm{~J} / \mathrm{cm}^{2}$ for $12 \mathrm{~s}$ on each point. Each session was repeated 3 times for one week, within $48 \mathrm{~h}$ between each session [9] (Table 2).

iii. Treatment of Oral dryness/hyposalivation

Extraoral application of diode laser $650 \mathrm{~nm}$ (LLLT Laser Bio:PDT: Soulagement de douleur par MG Consiliis) is attained with a total of 20 points (10 each side) at an energy density of $3 \mathrm{~J} / \mathrm{cm}^{2}$ for $12 \mathrm{~s}$ in a continuous and contact mode targeting major salivary glands (parotid and submandibular glands) and minor salivary glands in each side [9].

Five sessions of photobiomodulation were implemented for one week as follows: Monday Tuesday, Wednesday, Thursday, and Friday. After $24 \mathrm{~h}$ of each session, assessments of oral mucositis, oral dryness and dysgeusia were made according to the already mentioned scores and criteria. After each session, the severity of oral mucositis and oral dryness decreased, and taste perception improved. Oral mucositis decreased from grade 2 to grade 0 after five sessions of PBM. The patient scored 5 out of 5 on the taste identification score. The quantity of whole resting and stimulated saliva increased from 0.05 to 0.12 for the resting saliva and from 0.11 to 0.21 for the stimulated saliva. Table 1 shows the results.

Table 1. Results of the assessments of oral mucositis, dysgeusia, and oral dryness.

\begin{tabular}{ccccccc}
\hline Complication & T Initial & T1 & T2 & T3 & T4 & T5 \\
\hline $\begin{array}{c}\text { Oral mucositis score } \\
\text { according to the WHO }\end{array}$ & 2 & 2 & 1 & 1 & 0 & 0 \\
Dysgeusia & $3 / 5$ & $3 / 5$ & $4 / 5$ & $5 / 5$ & $5 / 5$ & $5 / 5$ \\
\hline Quantity of whole resting and stimulated saliva (Q-sal, $\mathrm{mL} / \mathrm{min}):$ & & \\
\hline Before stimulation & 0.05 & 0.06 & 0.06 & 0.07 & 0.1 & 0.12 \\
After stimulation & 0.11 & 0.15 & 0.16 & 0.18 & 0.25 & 0.27
\end{tabular}

$\mathrm{T}$ initial = before treatment, $\mathrm{T} 1=48 \mathrm{~h}$ after first session, $\mathrm{T} 2=48 \mathrm{~h}$ after the second session. $\mathrm{T} 3=48 \mathrm{~h}$ after the third session. T4 $=48 \mathrm{~h}$ after the fourth session. T5 $=48 \mathrm{~h}$ after the fifth session. Oral mucositis score according to WHO, dysgeusia measurements according to ISO taste identification score. Quantity of whole resting and stimulated saliva in $\mathrm{mL}$ per minute $(\mathrm{mL} / \mathrm{min})$. 
Table 2. Photobiomodulation parameters: applications and treatment protocol.

\begin{tabular}{|c|c|c|}
\hline Complication & Parameters & ZoneIrradiated \\
\hline Oral mucositis & $\begin{array}{l}\text { Intraoral application: } \\
\text { Diode laser } 980 \mathrm{~nm} \text {, energy density of } 4 \mathrm{~J} / \text { point } \\
\text { and a time of } 12 \mathrm{~s} \text { per point in a continuous and } \\
\text { contact mode } \\
\text { Extraoral application: } \\
\text { Diode laser } 980 \mathrm{~nm} \text {, energy density of } 4 \mathrm{~J} / \text { point, } \\
12 \mathrm{~s} \text { per point }\end{array}$ & $\begin{array}{c}\text { Intraoral application: } \\
4 \text { points on the tongue and } 2 \text { on } \\
\text { the oropharynx. } \\
\text { Extraoral application: } \\
\text { Lips, cutaneous surface corresponding to the } \\
\text { buccal mucosae, bilateral cervical } \\
\text { lymphatic chain. }\end{array}$ \\
\hline Dysgeusia & $\begin{array}{l}\text { Intraoral application } \\
\text { Diode laser } 980 \mathrm{~nm} .10 \text { points. Energy density } \\
\text { of } 3 \mathrm{~J} / \mathrm{cm}^{2} \text { for } 12 \mathrm{~s} \text { on each point. }\end{array}$ & $\begin{array}{l}\text { Intraoral application } \\
\text { Dorsal and lateral tongue. }\end{array}$ \\
\hline Oral dryness & $\begin{array}{c}\text { Extraoral application } \\
\text { Diode laser } 650 \mathrm{~nm} \text {. Energy density of } 3 \mathrm{~J} / \mathrm{cm}^{2} \\
\text { for } 12 \mathrm{~s} \text {. In continuous and contact mode. } \\
\mathrm{A} \text { total of } 10 \text { points }(1 \mathrm{~cm} \text { per point })\end{array}$ & $\begin{array}{c}\text { Extraoral application } \\
\text { Major salivary glands: parotid and } \\
\text { submandibular glands. Minor salivary glands } \\
\text { in each side. }\end{array}$ \\
\hline
\end{tabular}

\section{Discussion}

Oral complications induced by radiotherapy and/or chemotherapy represent an important clinical challenge, which affects the quality of life. These complications might delay cancer therapy or compromise with the adherence of patients to the treatment [13]. The most common oral and neck complications of cancer therapy are oral mucositis, dysphagia, dysgeusia, hyposalivation or xerostomia, osteonecrosis, radiation dermatitis, head and neck lymphedema, and trismus [8]. In this case report, the patient suffered from oral mucositis, dysgeusia and oral dryness. According to the National Cancer Institute (NCI), oral mucositis is defined as the inflammation of the mucous membrane, which lines the digestive tract from the mouth to the anus. Multiple mechanisms can lead to mucositis, including DNA damage, production of the reactive oxygen species and epithelial atrophy, bacterial translocation, and profound inflammation [14]. Eighty percent of patients receiving head and neck radiotherapy exhibit oral mucositis [9]. Currently, cohrane meta-analysis [15], systematic review and meta-analysis $[16,17]$, and other high-quality studies support the efficacy of photoboimodulation in the management of oral mucositis for patients undergoing chemotherapy or chemoradiotherapy. However, the authors agree that it is essential to recognize optimal PBM parameters per cancer treatment modality according to the severity of the symptoms of each patient. The Multinational Association of Supportive Care in Cancer and the International Society of Oral Oncology recommends the preventive use of photobiomodulation for patients receiving head and neck radiotherapy [11]. Another important complication of RT to the head and neck region is hyposalivation or oral dryness. In fact, $63-93 \%$ of patients show xerostomia or hyposalivation when the zone of radiation includes the salivary glands. Approximately all patients suffered from xerostomia as a result of radiation in the head and neck area due to RT [12]. A reduction in salivary glands' function has an important impact on the patients' quality of life and an increased burden of oral, dental care, and nutrition on a long term [18]. In contrast to oral mucositis, the literature on photobiomodulation for the management of hyposalivation is still limited. Therefore, this clinical report points out the potential use of PBM in the management of oral dryness or hyposalivation. Dysgeusia, commonly known as taste alteration during cancer therapy, is not well perceived in the literature; however, CT and RT cause dysgeusia by destroying rapidly dividing taste bud cells and olfactory receptor cells [19]. In this report, the patient underwent head and neck radiotherapy; therefore, oral mucositis, oral dryness and dysgeusia are expected symptoms. As a result, the patient's oral mucositis was treated, salivation and salivary function was significantly better, and taste perception was restored. This case report shows that photobiomodulation can effectively and safely reduce the severity of oral mucositis, oral dryness, and dysgeusia in only five sessions. Photobiomodulation can be considered as an effective and relatively fast approach to enhance the quality of life of cancer patients that present severe oral complications. It is important to note that these positive results were obtained using the parameters, applications, 
and treatment protocol suggested by international multidisciplinary board of researchers and experts in the area of photobiomodulation and supportive cancer care. As already noted, literature on the use of PBM in the management of dysgeusia and oral dryness is limited. Therefore, this study has contributed to making efficient progress in the research process where positive results were shown, so as to back previous literature. It is important to note that investigations are being made to see if PBM itself poses a carcinogenic threat or has the potential to alter (proliferate or invade) established tumor behaviors [20]. However, in this report, the risk was not there, because the application of PBM was made after cancer therapy.

\section{Conclusions}

Within the limitation of this clinical report, it can be concluded that the therapeutic use of photobiomodulation according to specific protocol is considered a good approach for the treatment of oral mucositis, dysgeusia, and oral dryness after head and neck radiotherapy.

Author Contributions: M.E.M., W.E.M. and S.N. performed the clinical examination, treatment and assessments. F.F., M.E.M. and S.N. wrote the manuscript. W.E.M. reviewed the literature. All authors reviewed the manuscript at allsteps.

Funding: No external funding was received for this research.

Acknowledgments: The authors declare that no financial support and no potential conflicts of interest with respect to the authorship and/or publication of this article was received.

Conflicts of Interest: The authors declare no conflict of interest.

\section{References}

1. Bensadoun, R.J.; Nair, R.G. Low-Level Laser Therapy in the Management of Mucositis and Dermatitis Induced by Cancer Therapy. Photomed. Laser Surg. 2015, 33, 487-491. [CrossRef] [PubMed]

2. Karu, T.I. Multiple roles of cytochrome c oxidase in mammalian cells under action of red and IR-A radiation. IUBMB Life 2010, 62, 607-610. [CrossRef] [PubMed]

3. Khakh, B.S.; Burnstock, G. The double life of ATP. Sci. Am. 2009, 301, 84-92. [CrossRef] [PubMed]

4. Hawkins, D.; Abrahamse, H. Biological Effects of Helium-Neon Laser Irradiation on Normal and Wounded Human Skin Fibroblasts. Photomed. Laser Surg. 2005, 23, 251-259. [CrossRef] [PubMed]

5. Silva, G.B.; Sacono, N.T.; Othon-Leite, A.F.; Mendonça, E.F.; Arantes, A.M.; Bariani, C.; Duarte, L.G.; Abreu, M.H.; Queiroz-Júnior, C.M.; Silva, T.A.; et al. Effect of low-level laser therapy on inflammatory mediator release during chemotherapy-induced oral mucositis: A randomized preliminary study. Lasers Med. Sci. 2015, 30, 117-126. [CrossRef] [PubMed]

6. Kuffler, D.P. Photobiomodulation in promoting wound healing: A review. Regen. Med. 2016, 11, $107-122$. [CrossRef] [PubMed]

7. Rogers, S.N.; Ahad, S.A.; Murphy, A.P. A structured review and theme analysis of papers published on 'quality of life' in head and neck cancer: 2000-2005. Oral Oncol. 2007, 43, 843-868. [CrossRef] [PubMed]

8. Zecha, J.A.; Raber-Durlacher, J.E.; Nair, R.G.; Epstein, J.B.; Sonis, S.T.; Elad, S.; Hamblin, M.R.; Barasch, A.; Migliorati, C.A.; Milstein, D.M.; et al. Low level laser therapy/photobiomodulation in the management of side effects of chemoradiation therapy in head and neck cancer: Part 1: Mechanisms of action, dosimetric, and safety considerations. Support. Care Cancer 2016, 24, 2781-2792. [CrossRef] [PubMed]

9. Zecha, J.A.; Raber-Durlacher, J.E.; Nair, R.G.; Epstein, J.B.; Elad, S.; Hamblin, M.R.; Barasch, A.; Migliorati, C.A.; Milstein, D.M.; Genot, M.T.; et al. Low-level laser therapy/photobiomodulation in the management of side effects of chemoradiation therapy in head and neck cancer: Part 2: Proposed applications and treatment protocols. Support. Care Cancer 2016, 24, 2793-2805. [CrossRef] [PubMed]

10. Migliorati, C.; Hewson, I.; Lalla, R.V.; Antunes, H.S.; Estilo, C.L.; Hodgson, B.; Lopes, N.N.; Schubert, M.M.; Bowen, J.; Elad, S. Mucositis Study Group of the Multinational Association of Supportive Care in Cancer/International Society of Oral Oncology (MASCC/ISOO). Systematic review of laser and other light therapy for the management of oral mucositis in cancer patients. Support. Care Cancer 2013, 21, 333-341. [CrossRef] [PubMed] 
11. Lalla, R.V.; Bowen, J.; Barasch, A.; Elting, L.; Epstein, J.; Keefe, D.M.; McGuire, D.B.; Migliorati, C.; Nicolatou-Galitis, O.; Peterson, D.E.; et al. Mucositis Guidelines Leadership Group of the Multinational Association of Supportive Care in Cancer and International Society of Oral Oncology (MASCC/ISOO). MASCC/ISOO clinical practice guidelines for the management of mucositis secondary to cancer therapy. Cancer 2014, 120, 1453-1461. [CrossRef] [PubMed]

12. Lončar, B.; Stipetić, M.M.; Baričević, M.; Risović, D. The Effect of Low-Level Laser Therapy on Salivary Glands in Patients with Xerostomia. Photomed. Laser Surg. 2011, 29, 171-175. [CrossRef] [PubMed]

13. Demez, P.H.; Moreau, P.R. The generalists' perception of quality of life in head and neck cancer. B-ENT 2015, 11, 163-171. [PubMed]

14. Sonis, S.T. A biological approach to mucositis. J. Support. Oncol. 2004, 2, 21-32. [PubMed]

15. Clarkson, J.E.; Worthington, H.V.; Furness, S.; McCabe, M.; Khalid, T.; Meyer, S. Interventions for treating oral mucositis for patients with cancer receiving treatment. Cochrane Database Syst. Rev. 2010, 4, CD001973. [CrossRef] [PubMed]

16. Bjordal, J.M.; Bensadoun, R.J.; Tuner, J.; Frigo, L.; Gjerde, K.; Lopes-Martins, R.A. A systematic review with meta-analysis of the effect of low-level laser therapy (LLLT) in cancer therapy-induced oral mucositis. Support. Care Cancer 2011, 19, 1069-1077. [CrossRef] [PubMed]

17. Oberoi, S.; Zamperlini-Netto, G.; Beyene, J.; Treister, N.S.; Sung, L. Effect of prophylactic low level laser therapy on oral mucositis: A systematic review and meta-analysis. PLoS ONE 2014, 9, e107418. [CrossRef] [PubMed]

18. Epstein, J.B.; Robertson, M.; Emerton, S.; Phillips, N.; Stevenson-Moore, P. Quality of life and oral function in patients treated with radiation therapy for head and neck cancer. Head Neck 2001, 23, 389-398. [CrossRef] [PubMed]

19. Boltong, A.; Aranda, S.; Keast, R.; Wynne, R.; Francis, P.A.; Chirgwin, J.; Gough, K. A prospective cohort study of the effects of adjuvant breast cancer chemotherapy on taste function food liking, appetite and associated nutritional outcomes. PLoS ONE 2014, 9, e103512. [CrossRef] [PubMed]

20. Sonis, S.T.; Hashemi, S.; Epstein, J.B.; Nair, R.G.; Raber-Durlacher, J.E. Could the biological robustness of low level laser therapy (photobiomodulation) impact its use in the management of mucositis in head and neck cancer patients. Oral Oncol. 2016, 54, 7-14. [CrossRef] [PubMed]

(C) 2018 by the authors. Licensee MDPI, Basel, Switzerland. This article is an open access article distributed under the terms and conditions of the Creative Commons Attribution (CC BY) license (http:/ / creativecommons.org/licenses/by/4.0/). 